\title{
Mesures de sécurité dans les cabinets médicaux
}

\section{Bruno Metzger}

Chef des conseils de sécurité, Police cantonale de Saint-Gall

Correspondance:

Sgtm Bruno Metzger Police cantonale de Saint-Gall Conseil de sécurité

Klosterhof 12 CH-9001 St-Gall
Ces mois derniers, la police a enregistré de nouveaux cambriolages dans des cabinets dentaires et médicaux dans toute la Suisse.

Le matin après ces actes effrontés, les praticiens concernés ont constaté que presque tous les appareils médicaux avaient été plus ou moins professionnellement démontés et déménagés. La police conclut que les cambrioleurs sont restés assez longtemps sur les lieux et que le transport des objets s'est fait par des véhicules adaptés.

Pour les cabinets mentionnés, l'interruption de l'activité a souvent duré plusieurs jours. Les appareils spéciaux ont notamment des délais de livraison de plusieurs mois. Même si l'assurance prend en charge les frais, les inconvénients subis sont en l'occurrence très désagréables.

Des mesures antivol sont dissuasives et efficaces. Etant donné le professionnalisme des auteurs, ces mesures doivent être sans compromis. Une installation anti-alarme conforme aux règles de l'art et couplée avec une centrale d'alarme privée est recommandée. Les postes de police de tous les cantons et des grandes villes offrent des conseils personnels sur place. Les conseillers, de par leur implication directe dans la police criminelle, peuvent profiter du savoir et de l'expérience de nos collaborateurs chargés du relevé des traces et de l'établissement des faits.

Les conseils sont indépendants et neutres. La police ne donne pas de recommandations d'entreprises.

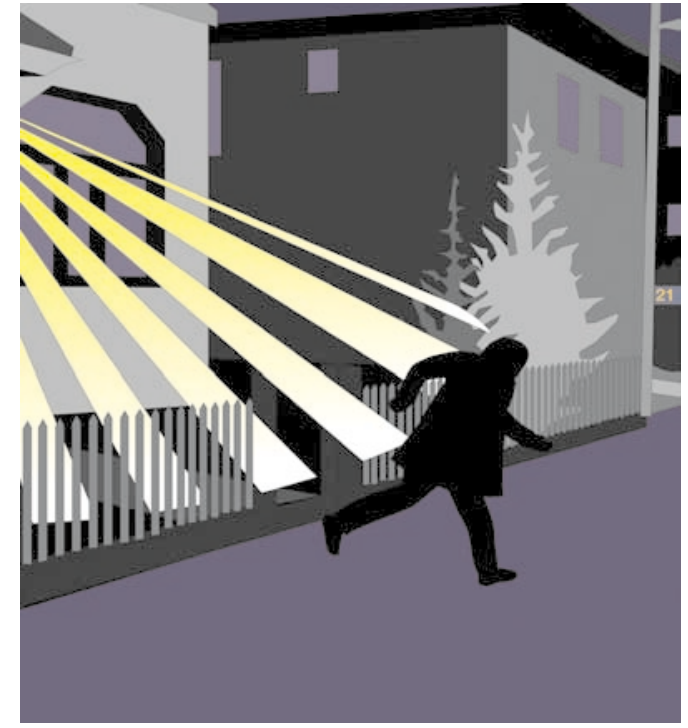

Illustration tirée de la brochure «Echec aux cambrioleurs!» consultable en ligne sous www.kriminalpravention.ch.

Vous trouverez les adresses de ces centres de conseils dans le bottin du téléphone ou sur la page d'accueil de la Prévention Suisse de la Criminalité (www.kriminalpravention.ch).

Les conseils sont une prestation le plus souvent gratuite. Si vous souhaitez des conseils, adressez-vous à la police du lieu où se situe votre cabinet.

La police est reconnaissante de recevoir une annonce rapide de faits suspects. 